\title{
Future Challenges to Health and Public Health Services in Canada
}

\author{
John Last, MD,DPH,FRACP, FRCPC,FFPH(UK), MD Honoris Causa, Uppsala and Edinburgh
}

$\int 100$ udging by the conventional indicators, there have been unprecedented improvements to the health of Canadians over the past 100 years (to our shame, First Nations and Inuit Canadians have not shared proportionately in these). Will the improvements continue? Or have we reached a peak from which we cannot expect to climb much higher? Will the present population health status be sustained in the future, or will it deteriorate? What challenges do public health specialists face in coming decades?

My track record in predicting the future has been mediocre, ${ }^{1}$ as often totally wrong as approximately right, so I shall not make specific forecasts. I will consider three kinds of future challenge likely to affect the health of Canadians, and suggest what public health leaders could do to protect Canadians from harm by these challenges. The three categories are environmental, social-demographic, and economic-fiscal. They are interconnected, which complicates effective responses by the public health sector and by society at large.

The environmental challenges are daunting. Climate change (global warming) is a reality that can no longer be denied. The scientific consensus is that a substantial part of it is due to human activity. ${ }^{2}$ The effects of climate change, notably increasing severity and frequency of extreme weather events (hurricanes, severe rain storms, floods, heat emergencies, etc.) are often aggravated by the environmental consequences of the way humans have laid waste to the earth, drastically modifying and destroying natural features tropical forests, coastal wetlands, etc. - that can insulate human habitats from some of the damage caused by violent weather. Mountains and hillsides stripped of vegetation are vulnerable to erosion, so soil is washed from the slopes as lethal mudslides, engulfing villages and towns, and the people who live in them. Tidal surges flood cities and settlements that have lost the wetlands and mangrove swamps that formerly absorbed the force of angry seas. This magnified the effects of Hurricane Katrina in 2005. The potential health impacts of climate change have been described and discussed in authoritative reports ${ }^{3}$ and enough climate-related events have occurred to validate theoretical models. Many direct observations in the past decade have exceeded the most extreme scenarios forecast by the models: change is happening faster than predicted. The European heat wave of 2003 caused the premature death of 35,000 to 50,000 , predominantly frail elderly and infirm people. Hurricane Katrina in 2005 was unequivocally related to unusually warm seawater in the Gulf of Mexico, a consequence of global warming. It cost about $\$ 100$ billion, killed at least 1,800 , and permanently displaced about 200,000 people. These were the first large numbers of internally displaced people in an affluent nation, but they will not be the last. Prolonged droughts in several parts of the world, including South Asia, Australia, North-Eastern and West Africa have led to crop failures and migration of many environmental refugees away from affected regions. In 2006, the UNHCR predicted a tenfold increase in numbers of environmental refugees from 5 million in 2005 to 50 million in $2010 .{ }^{4}$ Canada has been the destination for some, and there are likely soon to be many more. Climate models suggest that prolonged droughts are likely in the US mid-west and the Canadian prairies in coming decades; reduced river flow because of declining winter snows and retreat of Rocky Mountain glaciers aggravate the reduced soil moisture and carrying capacity of the prairies and the American Mid-West. Eastern Canada and North-eastern USA could face influxes of environmental refugees from the continental interior. Large numbers of migrating people present many problems for public health services. Climate change means global warming. The average annual number of extremely hot days will increase in the future; so heat emergencies on a comparable or greater scale than the European heat wave of 2003 could occur. In Climate Wars, ${ }^{5}$ Gwynne Dyer has a scenario in which millions of hungry and desperate refugees from the uninhabitable hot desert that was formerly the American MidWest, seek sanctuary, shelter and food in Canada. If that happens, the security challenges will outweigh the obvious challenges to public health services, so the scenario hardly bears thinking about, let alone planning for! But the general issue of public health services for refugees must be part of every disaster plan.

An equally important agenda item in public health planning for climate-related emergencies is to identify and protect groups who are especially vulnerable to climatic extremes like floods, droughts and heat waves. These include First Nations and Inuit who have often been pushed to the margins, to remote, inaccessible, floodprone localities; also included are frail elderly, persons with chronic cardiovascular and respiratory diseases, and infants and young children. Public health nurses and other community health workers can help to identify such groups and to prepare plans to ensure their protection from effects of extreme weather.

One happy thought about personal and domestic actions we can take to soften the impacts of climate change is that many such actions are in accord with health promotion practices: when we reduce our carbon footprint by walking or bicycling instead of driving gas-guzzling cars on short trips (say, up to 3-5 km), we are also toning up our cardiovascular system; and the 100-mile diet - eating only foods that come from within a radius of 100 miles - is arguably nutritionally healthier than the average supermarket shopping basket of foodstuffs.

Numerous environmental refugees are part of all scenarios of our socio-demographic future. Consider what happened in the $20^{\text {th }}$ century, a time of unprecedented global demographic turbulent change: an almost fourfold increase in numbers from 1.7 billion in 1900 to 6.4 billion in 2000; a shift from a predominantly (i.e., 95\%) rural population in 1900 to almost 50\% urban in 2000 (upwards of $80 \%$ urban in Canada); and massive international migrations that began in the very early $20^{\text {th }}$ century and rose to peaks after the two world wars when the numbers were swollen considerably by refugees and displaced persons. In the decades after World War II, Canada developed an efficient system to medically examine prospective immigrants and to absorb and settle them. This may have to be enhanced

Acknowledgement: I am grateful for advice and suggestions from Bob Spasoff and Ian McDowell, both from the Department of Epidemiology and Community Medicine, University of Ottawa. 
in the future. Accompanying the demographic changes and turbulent movements of people throughout the $20^{\text {th }}$ century, there were changes in family composition from extended multi-generation families with high birth rates in 1900 to nuclear two-generation families with low birth rates and few children in 2000, a dramatic increase in numbers and proportions of divorces and separations, and of singleparent mother-led families, and aging of populations (aging means a higher proportion of older and a smaller proportion of younger people). Populations in which many old people are isolated from their younger kin, and therefore often in need of support by social and community services rather than family support, present challenges for public health and personal health care services, and fiscal challenges too. The cultural preference for sons and selective abortion of female fetuses in both China and India has led to an excess of some 35 million males in these two nations, more than the total population of Canada, with social, cultural and perhaps human security consequences that may impact other countries far away, including Canada. Historically, nations with large numbers of young underemployed males have armed these men and waged war; critical shortages of at least one essential resource, fresh water for drinking and irrigation, could provide a reason for such wars in future; and war is the worst of all public health problems. Apart from doomsday scenarios involving future violent armed conflicts, other daunting sociodemographic problems loom in the future a quarter century and more from now. The most obvious is the rising proportion of older people who will require support by a declining proportion of people in active income-earning years. This means social and financial support. Many, perhaps most of the next generation of the elderly, will probably lack the financial safeguards of pensions that now reward long-term workers. Few fates are more miserable than a lonely and impoverished old age. Will adequate social security systems be maintained to provide the necessities of life for that future generation of the elderly - let alone the comforts and amenities many of us in that age group now enjoy? The elderly cohorts of the 2020s and beyond will be a greater drain on the public purse than those of the present time. Sources of financial support and the human resources of trained workers to support and care for the elderly people of the future, whether in their own homes or in some sort of institution, are barely adequate now, and few or no preparations to meet this challenge appear to have been made. Irresponsible political leaders who bribe the electorate with reckless tax cuts and distract with costly and unnecessary wars have emptied the public purse. When recession and unemployment reduce revenue further, our nation, like most others, is dismally unprepared, indeed almost without fiscal reserves, to meet these impending demographic and social challenges.

Among the social/cultural/demographic challenges that probably will loom larger in the future is maximizing the potential of young people born in Canada into families from ethnic, linguistic and often faith-based minority groups, even stigmatized groups. Alienation from mainstream Canadian society is observed among some members of these groups in several large cities in Canada. Drug abuse, violent crime, and unwanted early teenage pregnancy are preventable social problems that stem from these roots, with obvious implications for health. Their control and prevention demands intervention by skilled, well-trained community-based social workers, preferably recruited from the same cultural and ethnic background. This takes time, and more important, takes money that must be invested up front with no expectation of immediate benefit. It is difficult enough for public health administrators to advocate successfully for funds to maintain existing public health infrastructure. The chances of attracting sufficient funds to tackle this predictable and far-from-popular problem are even less, especially when dealing with right-wing governments that believe harsh punishments and more prisons are an appropriate response to these problems.

To a considerable extent, this fiscal reality is true of almost all requests for new and enhanced funding for public health infrastructure, especially in a constrained period such as the present. I have argued, though not successfully, that it is more important for a nation to protect its people from threats to their health than it is to protect them from the (illusory) threat of attack by a foreign power or by terrorists. Unfortunately, there are always more demagogues and pseudo-patriots in parliament and in the cabinet of its ruling party, prepared to argue aggressively for expenditure on weapons of war and on recruiting more police and building larger prisons, than there are eloquent advocates for public health.

There is scope in the public health sector for international collaboration - in which CPHA has an impressive record - to adapt and react to the impact of climate change and the related environmental challenges. CPHA could take leadership and Canadians with relevant expertise could get involved in preparing handbooks on establishing and running communities for environmental refugees, and could contribute to many other public health activities directed towards control of this challenging cluster of problems.

In the discourse on preparing to meet future challenges to health, we have an opportunity to take leadership in other ways, and to help shape public policy. Public health needs eloquent, forceful, and vigorous advocates who are able and willing to get engaged politically at national, provincial and local levels, so that we may be in better shape to meet these challenges. The Canadian people, including at least some of our elected political leaders, care about health. Concerns about health may help to leverage public and political opinion. If we can present the facts about health impacts of climate change and what steps we must take to minimize these impacts; if we can clearly explain to parliamentarians and other officials the nature of the social and cultural forces associated with the demographic changes underway in Canada; and if we can present the case for adequate financial and material support for staff and infrastructure, we may help to influence public policy on a wider front than the health sector alone.

\section{REFERENCES}

1. Last JM. The future of health and public health. Japanese J Public Health 1991;38:10,58-93.

2. Intergovernmental Panel on Climate Change: Climate Change 2007: Synthesis Report of the Fourth Assessment Report. Geneva, 2008. Available at: http://www.ipcc.ch/publications_and_data/publications_ipcc_fourth_assessment_report_synthesis_report.htm (Accessed December 3, 2009).

For details of impacts on Canada, see Seguin J (Ed.), Human Health in a Changing Climate: A Canadian Assessment of Vulnerabilities and Adaptive Capacity. Ottawa: Minister of Health, 2008. This report was commissioned by the Chrétien government; its release was delayed for some months by the Harper government, and it was eventually made public late on the Friday evening of a holiday weekend.

For a concise and comprehensive account of how to tackle the climate change crisis, see Lancet and University College London Institute for the Global Health Commission: Managing the health effects of climate change. Lancet 2009;373:1693-733.

3. McMichael AJ, Campbell-Lendrum DH, Corvalan CF, Ebi KL, Githeko A, Scheraga JD, Woodward A (Eds). Climate Change and Human Health; Risks and Responses. Geneva: WHO, WMO, UNEP, 2003.

4. For statistics on refugees and internally displaced persons, see http://www.unhcr.org (Accessed December 3, 2009).

5. Dyer G. Climate Wars. Toronto, ON: Random House Canada, 2008. 